\title{
Complex anterior chest wall reconstruction after extensive oncologic resections: a narrative review
}

\author{
Andrei I. Gritsiuta ${ }^{1 \wedge}$, Alexander Bracken ${ }^{1}$, Abbas E. Abbas ${ }^{2}$, Roman V. Petrov $^{2}$ \\ ${ }^{1}$ Department of Surgical Services, University of Pittsburgh Medical Center, Pittsburgh, PA, USA; ${ }^{2}$ Department of Thoracic Medicine and Surgery, \\ Division of Thoracic Surgery, Lewis Katz School of Medicine at Temple University, Philadelphia, PA, USA \\ Contributions: (I) Conception and design: All authors; (II) Administrative support: RV Petrov; (III) Provision of study materials or patients: AI \\ Gritsiuta, AE Abbas, RV Petrov; (IV) Collection and assembly of data: All authors; (V) Data analysis and interpretation: All authors; (VI) Manuscript \\ writing: All authors; (VII) Final approval of manuscript: All authors. \\ Correspondence to: Andrei I. Gritsiuta, MD, PhD. Department of Surgical Services, University of Pittsburgh Medical Center, 3600 Forbes Avenue, \\ Pittsburgh, PA 15213, USA. Email: gritsiutaai@upmc.edu.
}

Objective: This report serves to showcase four cases of rare, malignant primary neoplasms of the anterior chest wall [chondrosarcoma and basal cell carcinoma (BCC)] that thoracic surgeons may encounter, and different approaches to complex reconstruction that may be necessary following resection.

Background: Approximately $60 \%$ of the anterior chest wall neoplasms are malignant. The most common types of primary sternal tumors are chondrosarcoma and osteosarcoma. While guidelines for resection of these tumors have been previously described in the literature, guidelines regarding reconstructive techniques of the subsequent large defects are infrequently demonstrated.

Methods: The medical records of four adult patients with primary chest wall tumors who underwent resection of the sternum from October 2016 to March 2021 were retrospectively reviewed. Radical resection with tumor-free surgical margins offers the best chance for survival, but results in a wide full-thickness defect. Hence, closure of the anterior chest wall defect with skeletal reconstruction is an essential step of the procedure and allows us to highlight surgical techniques and materials that have been used over recent years. Methods described herein include skeletal reconstruction with various hardware or allograft, as well as defect coverage using regional flaps, free tissue transfer, and mesh.

Conclusions: Primary chest wall tumors of the sternum are an extremely rare diagnosis with a high malignancy rate. Full-thickness radical en-bloc resection is the most effective treatment option. Subsequent reconstruction of a wide chest wall defect is the most challenging aspect, though crucial in the preservation of the rigidity of the chest wall and protection of underlying structures. Different techniques and materials have been described without clear guidelines in treatment approaches; this paper serves to delineate and describe techniques that achieved successful outcomes.

Keywords: Chondrosarcoma; basal cell carcinoma (BCC); sternum resection; chest wall reconstruction

Received: 23 March 2021; Accepted: 18 June 2021; Published: 30 October 2021.

doi: $10.21037 /$ shc-21-8

View this article at: https://dx.doi.org/10.21037/shc-21-8

^ ORCID: 0000-0003-2265-9992. 


\section{Introduction}

Primary chest wall tumors are a very rare entity. Approximately $60 \%$ of these neoplasms are malignant, making up only $0.04 \%$ of all newly diagnosed cancers (1). The most common types of primary sternal tumors are chondrosarcoma and osteosarcoma. Surgical resection is the most effective treatment option; exceptions to this include Ewing sarcoma and solitary plasmacytoma. Surgery has several goals: full-thickness en bloc excision of the primary tumor, as well as anterior chest wall reconstruction. Wide resection is often required to ensure negative margins and prevent local recurrence; this frequently violates the stability of the chest wall and makes it vulnerable to paradoxical breathing movements. There are three types of sternal resection: partial sternectomy is performed for tumors located in the lower part of the sternum or manubrium (resection of less than $90 \%$ of the total sternal length), subtotal sternectomy, defined as resection with the preservation of the upper $2 \mathrm{~cm}$ of the manubrium and clavicles (resection of more than $90 \%$ of the sternum length), and total sternectomy.

Reconstruction is the most challenging aspect of the repair, though crucial to preserve the rigidity of the chest wall and protect underlying structures. Different techniques and materials have been described. Required criteria of the ideal prosthesis include rigidity and stability for preserved respiratory function, lack of immunoreactivity, resistance to infection, easy handling along with malleability, radiolucency and good functional and cosmetic results (2). Adequate soft tissue coverage by vascularized transposition flaps are necessary for preventing contamination and to assist with healing. The risks of infection and respiratory complications should be carefully weighed against the functional and protective benefits of reconstruction.

In this retrospective analysis, we present our experience in reconstructing different anterior chest wall defects following wide en bloc resections of primary neoplasms. We present the following article in accordance with the Narrative Review reporting checklist (available at https:// dx.doi.org/10.21037/shc-21-8).

\section{Patients and methods}

The medical records of four adult patients with primary chest wall tumors who underwent resection of the sternum from October 2016 to March 2021 were retrospectively reviewed. Patient demographics, clinical and pathological characteristics are provided in Table 1.

\section{Case 1: chondrosarcoma}

A 50-year-old male presented with a painful $7 \mathrm{~cm}$ mass on the right aspect of the sternal body. Per history, enchondroma of right third and fourth costal cartilages was resected three years prior. Review of previous slides established a diagnosis of low-grade chondrosarcoma, previously misdiagnosed as enchondroma.

Pre-operative CT imaging showed two heterogeneous, round masses at the level of the $3^{\text {rd }}-6^{\text {th }}$ right intercostal spaces measuring $2.7 \mathrm{~cm} \times 2.4 \mathrm{~cm} \times 1.6 \mathrm{~cm}$ and $5.0 \mathrm{~cm}$ $\times 4.8 \mathrm{~cm} \times 5.1 \mathrm{~cm}$ with defined borders and mineralized chondroid matrix, originating from cartilaginous segments extending to the sternal body medially. There was a solitary metastasis to the right lung $1.6 \mathrm{~cm}$ in diameter (Figure 1).

An incisional biopsy established a diagnosis of recurrent grade 2 chondrosarcoma. Radical full-thickness en bloc resection of the sternal body with $2 \mathrm{~cm}$ margins including the right fifth and sixth costal cartilages was performed through a hemi-clamshell skin incision. In addition, resection of the remaining cartilage of the third and fourth ribs was performed followed by a wedge resection of the right lower lobe. Stability of the rib cage was achieved by implantation of two titanium plates (Matrix Rib Fixation System, DePuy Synthes CMF, West Chester, PA, USA) (Figure 2A). Soft tissue coverage of the hardware was achieved with right pectoralis major and serratus anterior muscle flaps.

The patient was discharged without complication on postoperative day 11. Microscopically, the diagnosis of grade 2 chondrosarcoma had been confirmed with lung metastasis and R0 resection. No adjuvant treatment was recommended. At 12 months follow-up, there was no radiologic or clinical evidence of recurrence. The patient was lost to further follow-up (Figure 2B).

\section{Case 2: chondrosarcoma}

A 39-year-old female with a history of trauma to the anterior chest wall presented with a 3-month history of pain and swelling at the upper sternal region. Pre-operative enhanced CT imaging demonstrated an osteolytic 4.4 $\mathrm{cm} \times 4.7 \mathrm{~cm} \times 1.8 \mathrm{~cm}$ manubrial mass without anterior mediastinum invasion (Figure 3). A diagnosis of a primary sternal grade 2 chondrosarcoma was established by 
Table 1 Summary of patients with sternal tumors

\begin{tabular}{|c|c|c|c|c|c|c|c|c|c|}
\hline Case & Age & Sex & Tumor & Tumor size $(\mathrm{cm})$ & Defect size $(\mathrm{cm})$ & Location & Resection & Reconstruction & Follow-up \\
\hline 2 & 39 & $\mathrm{~F}$ & CS & $4.4 \times 4.7 \times 1.8$ & $12 \times 10$ & Manubrium & $\begin{array}{c}\text { Subtotal } \\
\text { sternectomy }\end{array}$ & $\begin{array}{l}\text { Titanium plates, } \\
\text { omental flap }\end{array}$ & 47 months \\
\hline 3 & 63 & $M$ & CS & $8.2 \times 7.4 \times 9.3$ & $15 \times 5$ & Manubrium & $\begin{array}{c}\text { Subtotal } \\
\text { sternectomy }\end{array}$ & $\begin{array}{l}\text { MMA, prolene } \\
\text { mesh }\end{array}$ & - \\
\hline
\end{tabular}

BCC, basal cell carcinoma; CS, chondrosarcoma; MMA, methyl methacrylate.
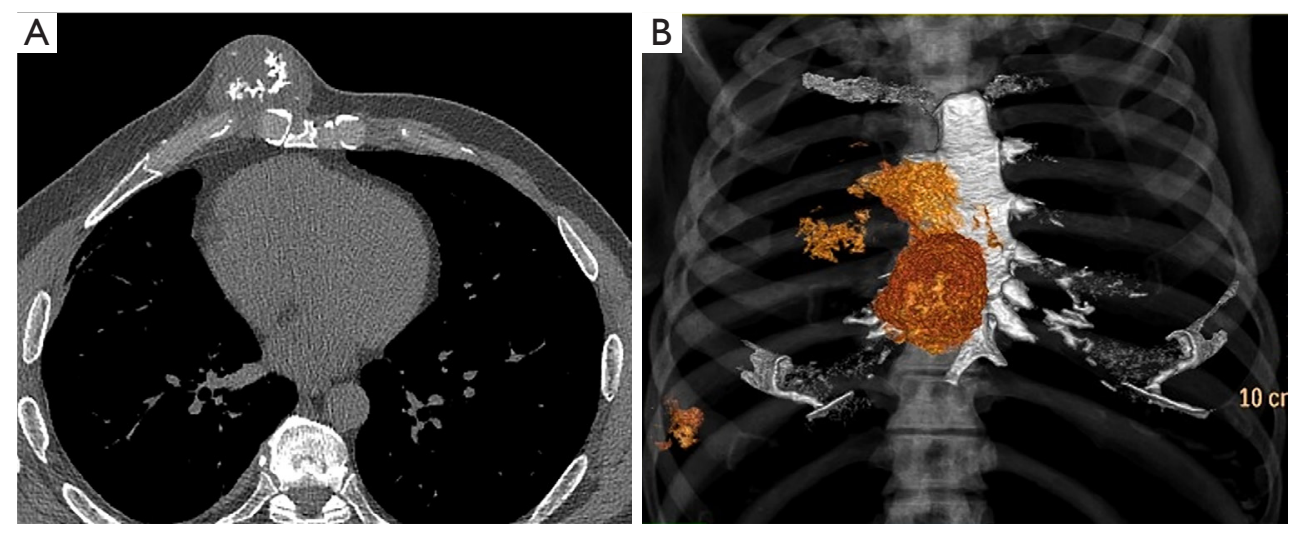

Figure 1 Preoperative CT images: (A) axial plane and (B) 3-D reconstruction showing two heterogeneous neoplasms originate from $3^{\text {rd }}-6^{\text {th }}$ costal cartilages invading sternal body on the right side with no signs of mediastinal invasion.

incisional biopsy.

The tumor was resected en bloc through a midline T-shaped skin incision with the manubrium, upper third of the body of the sternum, two costal cartilages, and sternoclavicular joints bilaterally with $2 \mathrm{~cm}$ surgical margins, resulting in a large defect measuring $12 \mathrm{~cm} \times 10 \mathrm{~cm}$ with exposed mediastinum (Figure 4). An omental flap was harvested for closure of the chest wall defect (Figure $5 A, B$ ). A bone cement prosthesis was created based on CT images. Prosthetic sternum was connected to both clavicles with steel wires and to the remaining part of the sternum and second ribs bilaterally with titanium plates (Matrix Rib Fixation System, DePuy Synthes CMF, West Chester, PA, USA) (Figure 5C,D).

The final pathologic examination confirmed the diagnosis of a grade 2 primary sternal chondrosarcoma with clear resection margin (R0). No adjuvant treatment was recommended. The patient was discharged uneventfully on postoperative day 22. Chest CT images a month postoperatively confirmed proper position of the sternal prosthesis (Figure 6). The patient remained well 47 months after resection without any signs of recurrence.

\section{Case 3: chondrosarcoma}

A 63-year-old male presented with a painful mass of his anterior chest wall, slowly increasing in size over the course of several years. The patient underwent CTguided biopsy of the tumor and was diagnosed with a grade 2 chondrosarcoma of the manubrium. PET-CT scan revealed no metastatic disease. Pre-operative enhanced CT imaging and MRI demonstrated an expansile lytic lesion measuring $8.2 \mathrm{~cm} \times 7.4 \mathrm{~cm} \times 9.3 \mathrm{~cm}$ involving soft tissue components, the center of the sternum and manubrium, and a poor tissue plane to the adjacent aortic arch which did not allow for exclusion of invasion of the mediastinum structures (Figure 7).

Resection was performed through a midline skin incision 

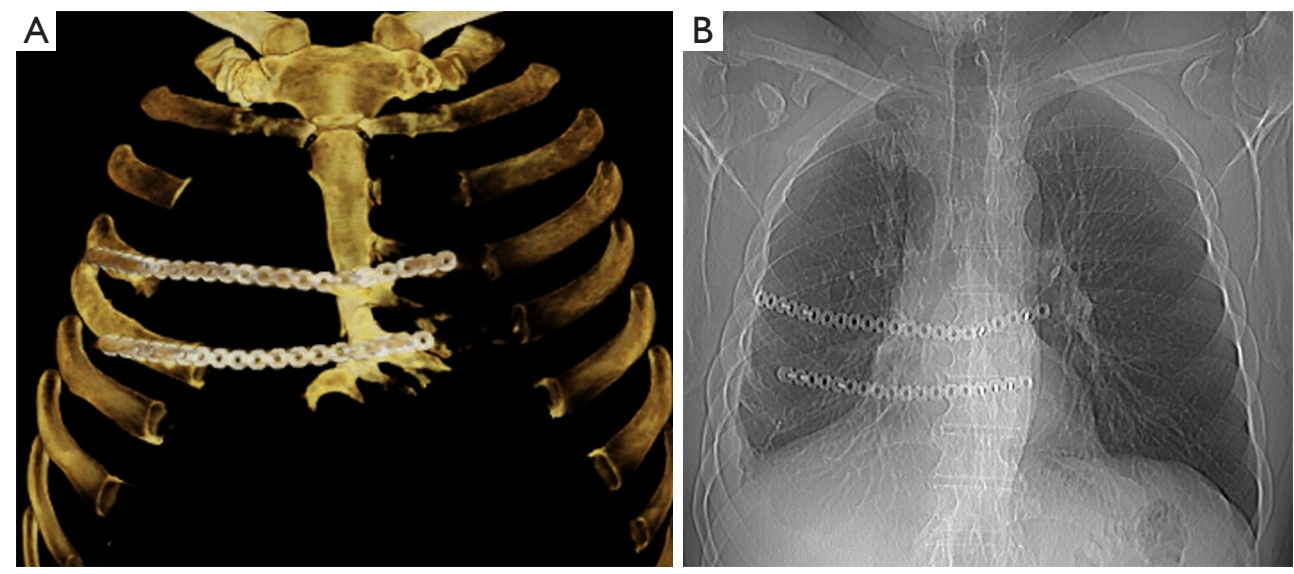

Figure 2 Postoperative images showing implanted two titanium plates in a proper position: (A) bony chest CT image with 3-D reconstruction; (B) chest X-ray one month postoperatively.

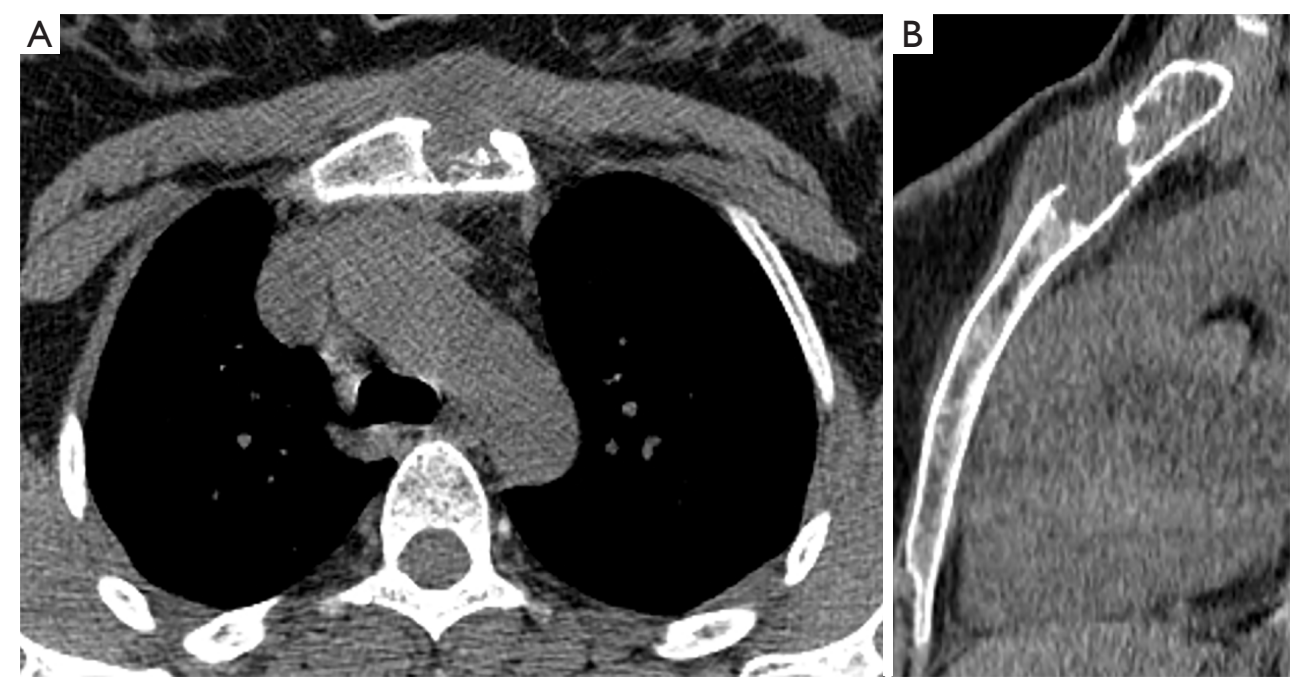

Figure 3 Preoperative CT images showing osteolytic hypodense neoplasm originating from the manubrium with destruction of bony cortex: (A) axial and (B) sagittal planes.

over the sternum. The sternal body was transected at the level of the $3 \mathrm{rd}$ intercostal space $(2 \mathrm{~cm}$ distal to the end of the manubrium), and an upper partial sternotomy was performed. The internal thoracic arteries were divided bilaterally using hemo-clips. Involved cartilages of the $1^{\text {st }}-3^{\text {rd }}$ ribs were transected approximately $1.5 \mathrm{~cm}$ lateral to the costo-sternal junction. The right and left clavicles were divided $1 \mathrm{~cm}$ lateral to the sternal junction and the whole mass was retracted cranially. The posterior aspect of the tumor was dissected free from the anterior mediastinal tissue without sign of its extension into vascular or cardiac structures, and the tumor was removed en bloc with $2 \mathrm{~cm}$ margins. The resulted defect of the anterior chest wall was reconstructed with Marlex mesh-methylmethacrylate using a "sandwich" technique, and steel wires were placed in the mid-lower sternum (Figure 8A). The prosthesis was covered with bilateral advancement pectoralis major muscle flaps, and the sternal wire was covered by the elevated rectus abdominis fascia (Figure 8B).

The final pathologic examination confirmed the diagnosis of a grade 2 primary sternum chondrosarcoma with a clear resection margin (R0). The patient was discharged uneventfully on postoperative day 7. The first follow-up has been scheduled. 

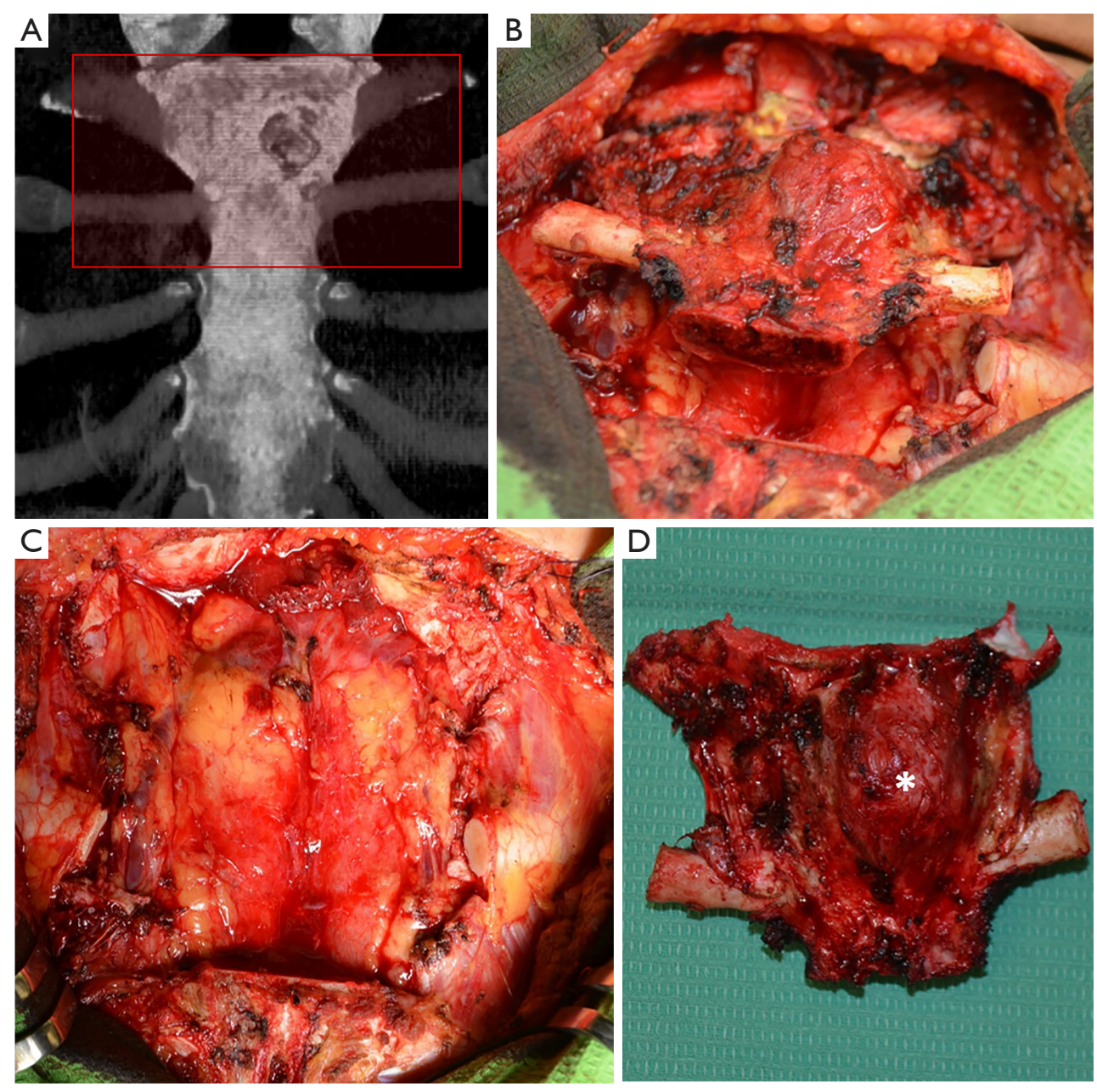

Figure 4 Preoperative CT image planning and intraoperative view: (A) resection volume is shown in red square; (B) en bloc resection of the manubrium, upper third of the sternum, first and second costal cartilages and sternoclavicular joints bilaterally; (C) the $12 \mathrm{~cm} \times 10 \mathrm{~cm}$ anterior chest wall defect; (D) resection specimen (asterisk).

\section{Case 4: basal cell carcinoma (BCC)}

A 73-year-old male, without history of any prior medical evaluation, presented to the emergency department with pulsatile bleeding from a large anterior chest wound secondary to erosion of the right internal mammary artery. Bleeding was controlled at that time using suture. Per the patient's report, the wound had been present for over 20 years, starting as a skin nevus. On presentation, the wound measured $14 \mathrm{~cm} \times 12 \mathrm{~cm}$ in size with exposed sternum, rib cartilages and pericardium (Figures 9,10A).

After a short pre-operative evaluation that revealed untreated diabetes, chronic obstructive pulmonary disease and congestive heart failure with an ejection fraction of $25 \%$, the patient was medically optimized and brought in for resection on hospital day 4. During the procedure, the body of sternum, bilateral $3^{\text {rd }}-8^{\text {th }}$ ribs, and pericardium were resected with $2 \mathrm{~cm}$ margins (Figure 10B). The bottom of the wound extended through the pericardium, requiring resection and reconstruction with biological mesh (Figure 10C). A $6 \mathrm{~mm}$ right pulmonary nodule was also resected. The extensive right pleural cavity defect was closed with a thymic flap, elevated from the pericardium to avoid empyema. Due to contamination of the wound, use of hardware for skeletal reconstruction was chosen against. Coverage of the wound was challenging due to the extent of the resection, contamination, and sacrifice of bilateral internal mammary arteries and was achieved with an omental flap with a plan for delayed skin grafting 

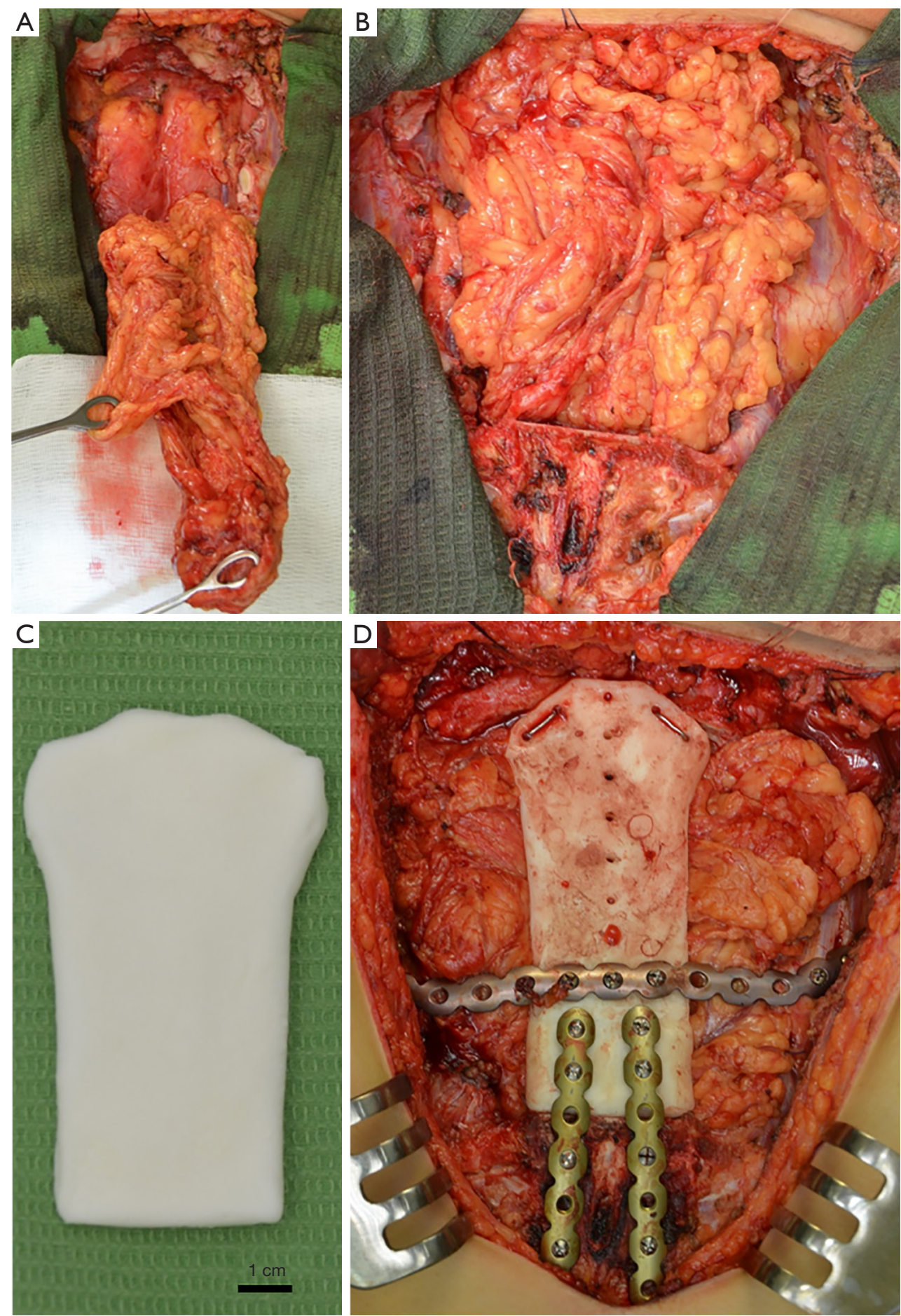

Figure 5 Intraoperative view: (A) harvested omental flap; (B) placement of the pedicled omental flap to the chest wall defect; (C) sternal prosthesis design; (D) final chest wall reconstruction with bone cement prosthesis and three titanium plates. 

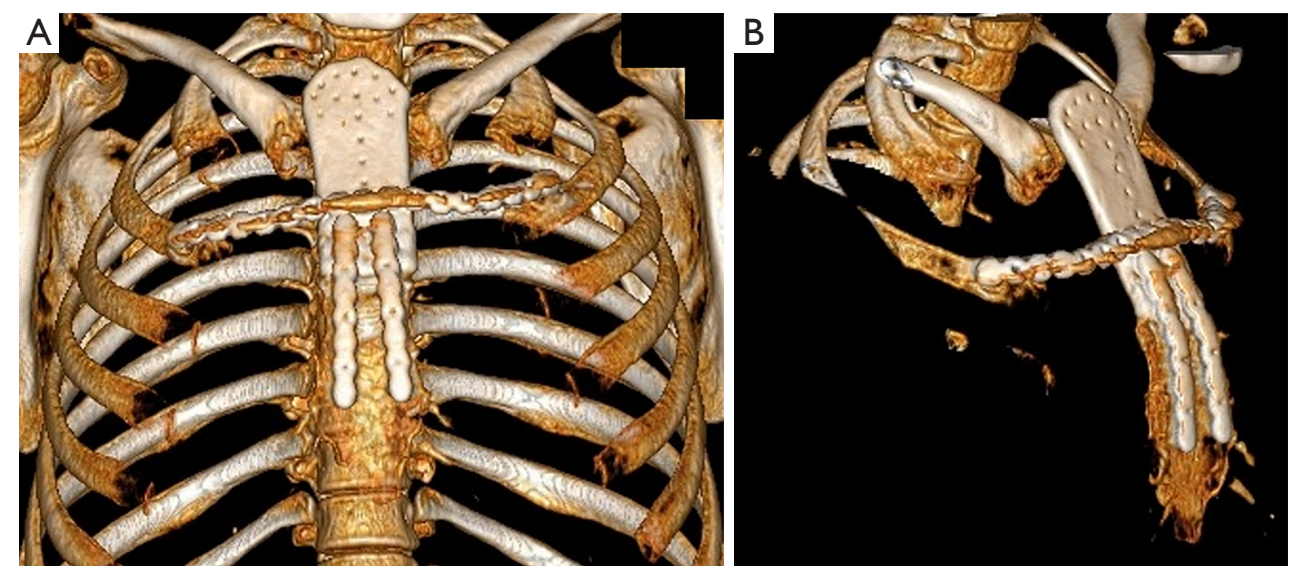

Figure 6 Postoperative 3-D reconstruction of the bony thorax and sternal prosthesis: (A) frontal and (B) lateral view.
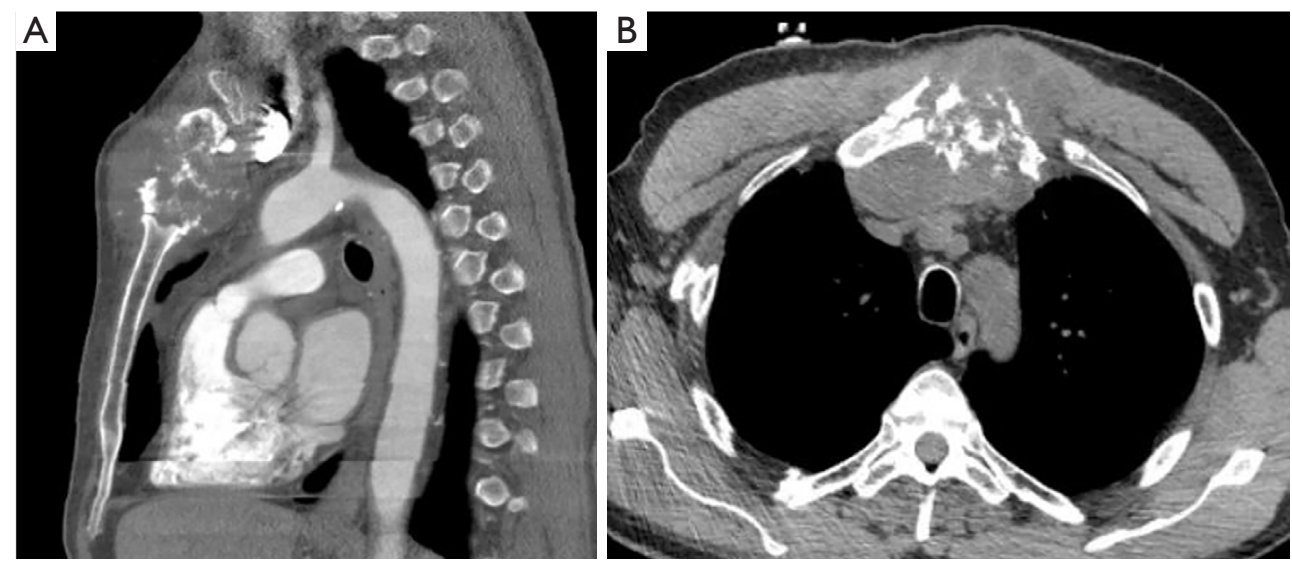

Figure 7 Preoperative chest CT images showing large, expansile, osteolytic lesion $8.2 \mathrm{~cm} \times 7.4 \mathrm{~cm} \times 9.3 \mathrm{~cm}$ with soft tissue components centered of sternum manubrium with direct extension to the anterior mediastinum: (A) sagittal and (B) axial planes.

(Figure 10D). Of note, rectus abdominis free flaps with anastomoses to inferior epigastric arteries could have also been an effective form of reconstruction in this case.

The final pathologic diagnosis was consistent with BCC extending to the chest wall, sternum, pericardium, and metastasis to the lung, as well as osteomyelitis of the sternum and bilateral $3^{\text {rd }}-8^{\text {th }}$ ribs (Figure 11).

The patient had a prolonged and complicated hospital course, requiring multiple interventions, including tracheostomy and jejunostomy. Eventually, the patient recovered well and was discharged on postoperative day 47 to a nursing facility. He underwent successful delayed split thickness skin graft on postoperative day 109 with $100 \%$ take and returned to independent living (Figure 12). Despite lack of skeletal reconstruction, the chest wall remained stable from tight scar tissue anteriorly. The patient refused to wear a protective chest orthosis, and he passed away 28 months later from unrelated causes.

\section{Discussion}

\section{Chondrosarcoma}

Chondrosarcoma, although rare, is the most common primary malignant cartilage-forming neoplasm of the thoracic cage. Chondrosarcoma accounts for $20-70 \%$ of all chest wall tumors and approximately $30 \%$ of all malignant bone tumors $(3,4)$. In the chest wall, ribs are the most commonly affected (costal type, approximately $80 \%$ ). Combined involvement of ribs and sternum (costosternal type) or sternum alone (sternal type) accounts for 

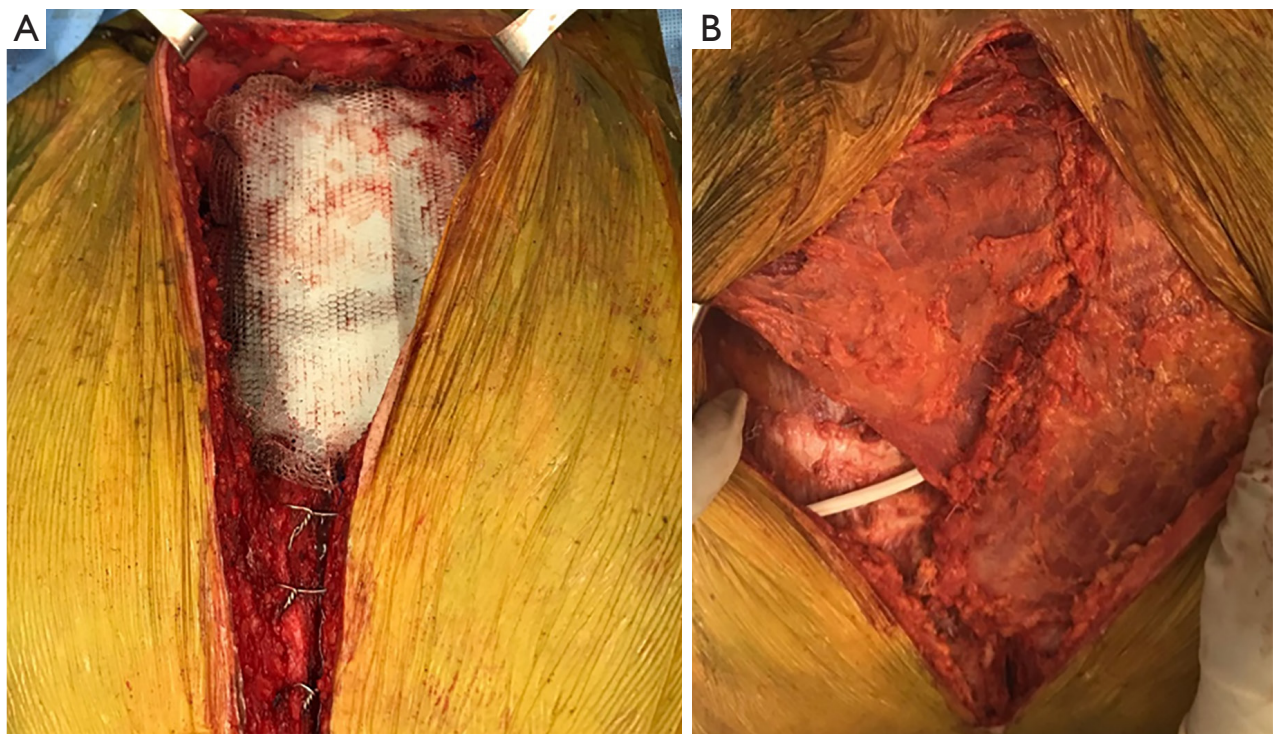

Figure 8 Intraoperative view: (A) surgical defect after en bloc subtotal sternectomy is reconstructed with Marlex mesh-methylmethacrylate "sandwich" technique; (B) prosthesis is covered by bilateral advancement pectoralis major muscle flaps.
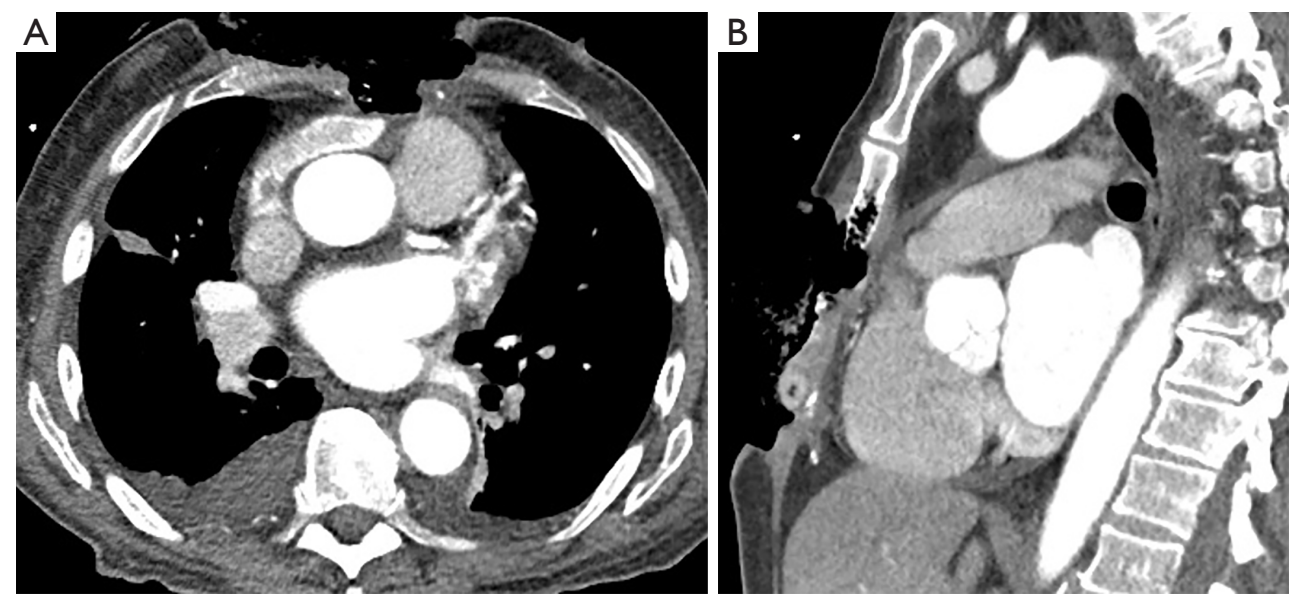

Figure 9 Preoperative chest CT images showing wide lesion with tumor erosion of the sternum: (A) axial and (B) sagittal planes.

$20 \%$ of cases $(3,5)$. Chondrosarcoma is most frequently diagnosed in the fourth and fifth decades of life (median age of 55 years), with a slight male predominance (4). Bawa et al. (6) described sternal chondrosarcoma in a six-year-old child, where an anterior chest wall defect did not require reconstruction.

Radical resection with a wide margin is the standard of care, and radio- or chemotherapy have not shown an improvement in outcomes. In many large series, the 5-year survival rate ranges between $64 \%$ and $92 \%(4,5,7-10)$. A high-grade tumor, size larger than $10 \mathrm{~cm}$, recurrence, and incomplete resection (R1) are negative predictors in these patients $(4,10,11)$.

The single most important factor for improved survival and lower recurrence is a radical tumor excision with adequate surgical margins (10). R1 resection is associated with a high incidence of recurrence. Gitelis et al. (12) reported a recurrence rate of $6 \%$ for radical resection compared with $69 \%$ for incomplete resection. McAfee et al. (11) evaluated 96 patients with chondrosarcoma of the chest wall at the Mayo Clinic. Ten-year survival and recurrence rates were $96 \%$ and $50 \%$ for wide resection 

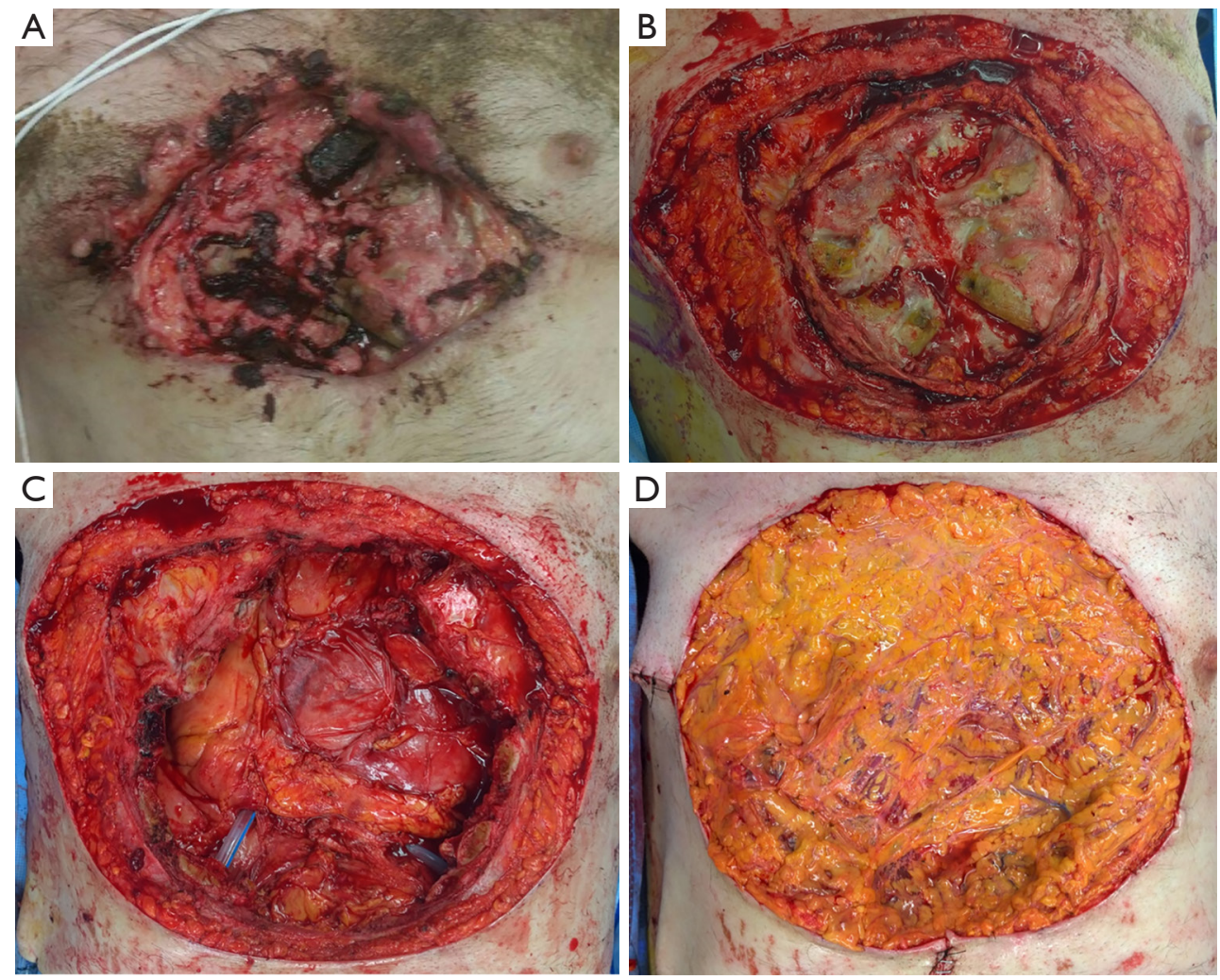

Figure 10 Preoperative ulcerated cutaneous wound $14 \mathrm{~cm} \times 12 \mathrm{~cm}(\mathrm{~A})$ and intraoperative images: (B) anterior chest wall defect $22 \mathrm{~cm} \times 18$ $\mathrm{cm}$ after subtotal sternectomy; (C) the pericardial defect is reconstructed with biological mesh; (D) omental flap on the left gastroepiploic artery is positioned applications to the chest wall defect.
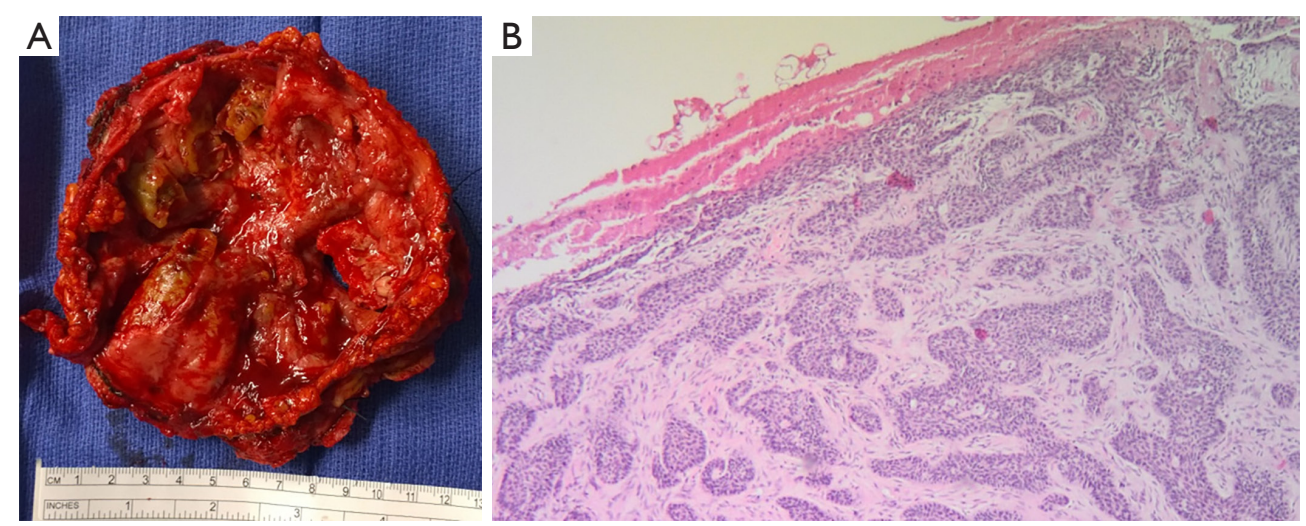

Figure 11 Pathologic assessment of the surgical specimen: (A) macroscopic examination of the excised en bloc basal cell carcinoma of the anterior chest wall; (B) H\&E-stained section of the skin specimen: small tumor islets into the dermis composed of cells with elongated ovoid nuclei, focal peripheral palisading with low cellular differentiation and stroma hyalinization, 100×.

versus $65 \%$ and $17 \%$ for local excision, respectively. Another Mayo Clinic series of 24 patients with chest wall chondrosarcoma was reported by Fong et al. (7) with a
5 -year overall survival rate of $92 \%$. Inadequate margins were associated with a statistically significant decrease in overall survival: $50 \%$ compared with $100 \%$. All patients 

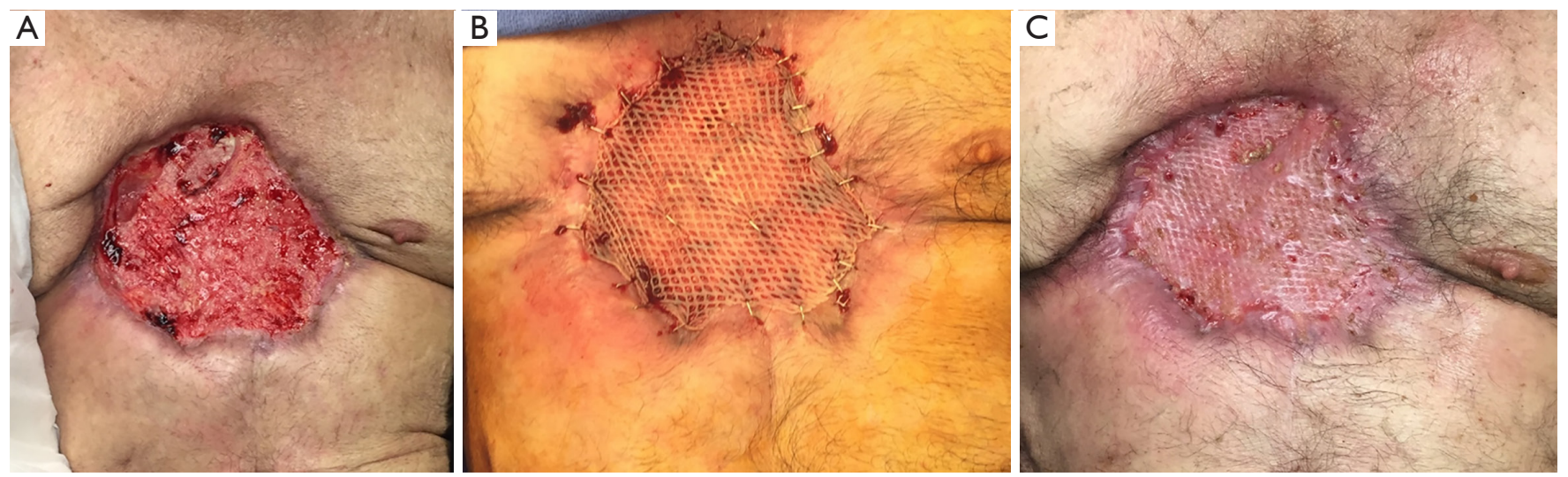

Figure 12 Postoperative evaluation of the patient after basal cell carcinoma resection: (A) POD 79: clean granulating wound, contracted to $10 \mathrm{~cm} \times 8 \mathrm{~cm}$; (B) POD 109: split-thickness skin graft; (C) POD 118: full take of skin graft.

with inadequate resection received adjuvant radiotherapy. A minimum of $2 \mathrm{~cm}$ margins for low-grade and $6 \mathrm{~cm}$ margins for high-grade tumors are required to minimize the risk of recurrence (13). Widhe et al. (9) reported 10-year survival for the 106 patients with chest wall chondrosarcoma of $92 \%$ for resections completed with wide margins versus $15 \%$ for those with $\mathrm{R} 1$ resection. Recurrence rates as high as $93 \%$ and 10 -year survival of $14 \%$ were reported for palliative chondrosarcoma excision (11).

Other prognostic factors should not be ignored. Marulli et al. (4) indicated histological grading as a significant predictor of survival and distant recurrence. The overall 5-year survival rate for Grades I, II and III were 97\%, 57\%, and $39 \%$, respectively. Univariate and multivariate analysis indicated low-grade type, negative surgical margin, age under 55, and tumor size less $6 \mathrm{~cm}$ as predictors of better survival. Ahmad et al. (14) summarized the results of 78 sternal resections, $21 \%$ of which were for primary chest wall chondrosarcoma. Marlex mesh-methylmethacrylate composite (54\%) and pectoral muscle flaps (25\%) were the most common skeletal reconstruction and soft tissue coverage options. Radical tumor resection was associated with significantly improved 5 -year overall survival rate $(84 \%$ versus $20 \%$ ), while the presence of a primary malignant tumor, complete sternectomy, and R0 resection were associated with improved recurrence-free probability, shown by univariate analysis. Multivariate analysis indicated the presence of a primary malignant tumor and complete sternectomy as prognostic factors associated with improved recurrence-free survival. Gao et al. (8) recently reported the outcomes of 779 patients with chest wall chondrosarcoma. The independent predictive factors based on multivariate analysis of overall survival and cancer-specific survival were age at presentation (over 40), tumor grade, tumor stage, surgical resection, and radiotherapy. The overall and cancer-specific 5-year survival rates were $76.8 \%$ and $83.6 \%$, respectively.

\section{$B C C$}

BCC is a non-melanotic skin cancer that arises from the basal cells of the lower layer of the epidermis, grows slowly, and has an extremely low metastatic potential. It is the most common type of skin cancer, accounting for more than $80 \%$ of all cases. Aggressive BCC larger than $5 \mathrm{~cm}$ is highly malignant, often metastasizing and defined by the American Joint Committee on Cancer as Giant BCC, which accounts for $<1 \%$ of all BCC (15). Giant BCC most often occurs in the seventh decade of life with a male predominance (2:1 ratio), and a patient's neglect of symptoms for greater than one year is a typical presentation $(16,17)$. BCC is most frequently $(80-85 \%)$ located on the head and neck, while localization on the trunk is extremely rare (18). Only a few reports of giant BCC in the anterior chest wall have been described (Table 2).

BCC can be locally destructive with invasion of soft tissue, cartilage and bone if left untreated. In our case, the patient presented with neglect for over 20 years, and a large, locally destructive anterior chest $\mathrm{BCC}$ with erosion to the level of right ventricle. The plan of care is affected by the risk profile of the tumor. Multiple modalities are used in the care of BCC, including electrodessication and curettage, surgical excision, topical 5-FU or imiquimod, cryosurgery, intralesional injection, and photodynamic therapy (19). 
Table 2 Surgical treatment of the giant BCC in anterior chest wall

\begin{tabular}{|c|c|c|c|c|c|c|}
\hline Author & Year & Sex & Age & Location & Resection & Reconstruction \\
\hline Santos et al. (17) & 2016 & $\mathrm{~F}$ & 72 & Manubrium and body & ST sternectomy & $\begin{array}{l}\text { PM muscle flaps, porcine acellular dermis, } \\
\text { VRAM flap }\end{array}$ \\
\hline Lorenzini et al. (18) & 2005 & M & 81 & Body & None & - \\
\hline Lackey et al. (19) & 2007 & M & 43 & Soft tissue & $\begin{array}{l}\text { Involved skin, } \\
\text { subcutaneous tissue }\end{array}$ & TRAM flap \\
\hline Cunnick et al. (20) & 1997 & $\mathrm{~F}$ & 54 & Body & ST sternectomy & LD muscle free flap, split skin graft \\
\hline Nystrom et al. (23) & 2014 & M & 69 & Manubrium and body & ST sternectomy & $\begin{array}{l}\text { Omental flap, simplex bone cement, Gore- } \\
\text { Tex patch, split skin graft }\end{array}$ \\
\hline
\end{tabular}

ST, subtotal; LD, latissimus dorsi; TRAM, transverse rectus abdominis myocutaneous; VRAM, vertical rectus abdominis myocutaneous; $\mathrm{PM}$, pectoralis major.

Radiotherapy can be used for advanced and extended lesions in patients that are not surgical candidates, which allows achievement of $67 \%$ local control (24). Wide local $(2-3 \mathrm{~cm})$ excision with histologically confirmed tumor-free margins is the most effective treatment option. Even after successful surgery, in the case of giant BCC, the local recurrence rate is $38 \%$ and metastasis was reported in $18 \%$ of patients (15).

Left untreated, BCC can become locally destructive to the point that surgical resection is not an option due to the large size of the tumor or proximity to vital structures. As seen in our case, the lesion had been progressively invading the chest wall to expose the heart, and was also metastatic to the lung by the time of presentation. Therapies for such advanced disease have generally been extremely limited, and FDA approved hedgehog inhibitors are not helpful.

The first report of a metastatic BCC to the anterior chest wall with invasion of the sternum was made by Cunnick in 1997 (20). The sternal body and lower twothirds of the manubrium were resected with the left first seven ribs and costal cartilages. The defect was closed with a left latissimus dorsi muscle free flap, anastomosed to the inferior thyroid artery, and additional split thickness skin grafting was utilized. Vallely et al. (21) used a $2 \mathrm{~mm}$ Gore-Tex patch in addition to a full-thickness rotational left latissimus dorsi flap and split thickness skin grafting.
In a comprehensive review of 51 patients with giant BCC since 1969 by Archontaki et al. (15), tumor location on the anterior chest wall was observed only in one case, but without invasion to the sternum. Transverse rectus abdominis myocutaneous (TRAM) flaps and synthetic mesh were chosen for reconstruction. After partial necrosis of the myocutaneous flap, the defect was covered with an ipsilateral pedicled latissimus dorsi flap. The patient received adjuvant radiotherapy. Warbrick-Smith et al. (22) published a case of giant BCC on the lower antero-lateral chest wall. Reconstruction was made with prolene mesh, porcine acellular dermis, an omental flap, a pedicled vertical rectus abdominis myocutaneous (VRAM) flap and split thickness skin grafting. Nystrom et al. (23) described a case of giant BCC with sternal invasion. The tumor was resected en bloc and resulted in a defect $17 \mathrm{~cm} \times 15 \mathrm{~cm}$ that was reconstructed with an omental flap, Simplex bone cement, Gore-Tex mesh, split thickness skin grafting, and the wound was covered with a vacuum-assisted closure device. Subsequently, the mesh was removed following purulent drainage. Santos et al. (17) presented a 72-year-old female with giant BCC found on routine medical examination. Partial sternectomy with a minimum of $1 \mathrm{~cm}$ margins was performed followed by radiation and chemotherapy. Bony and soft tissue defects were reconstructed with bilateral 
pectoral advancement flaps, acellular dermal matrix mesh, and a right VRAM flap.

The tumor size and proximity to vital structures noted in our patient typically would have excluded surgical intervention as a first-line therapy. However, the acute bleeding and osteomyelitis on presentation precluded the use of pre-operative chemotherapy, and necessitated a higher urgency for resection. Furthermore, this dramatic presentation impacted the reconstruction choices after resection. First, the infection disallowed hardware use for the skeletal reconstruction. Second, the extent of the wound required sacrifice of both internal mammary arteries and excluded the use of rectus abdominis flaps. Finally, chest wall instability prohibited lateral positioning for the latissimus dorsi flap. Staged closure with an omental flap, vacuum therapy and delayed skin grafting without skeletal reconstruction was carried out successfully, providing structural integrity and an acceptable cosmetic result per patient report.

\section{Reconstructive techniques}

Radical resection with tumor-free surgical margins offers the best chance for survival, but results in a wide fullthickness defect. Hence, closure of the anterior chest wall defect with skeletal reconstruction is an essential step of the procedure and allows us to highlight surgical techniques and materials that have been used over recent years. That being said, the comprehensive review of all possible reconstructive methods is beyond the scope of this article.

In rare cases when the defect is less than $5 \mathrm{~cm}$, primary closure without advanced chest wall reconstruction is sufficient (25). There is no universally accepted prosthetic material. Traditionally, the type of reconstruction is based on surgeon preference and individual anatomy. However, the ideal prosthesis should have basic characteristics of rigidity, malleability, inertness and radiolucency. The reconstruction techniques described to date include nonrigid [such as polytetrafluoroethylene (PTFE) or Gore-Tex patch, polypropylene (PPM) or Marlex mesh, vicryl mesh, polyglactin mesh, biologic mesh) $(4,5)]$, rigid materials [such as Marlex mesh-methylmethacrylate (MMM) composites (26), shield-shaped titanium prosthesis (27), including 3D-printed (28), hydroxyapatite tricalcium phosphate (ceramic) prosthesis (29), acrylic cement (30), titanium mesh (31), titanium plates (STRATOS system, MatrixRIB, MDF Medica) $(32,33)$, including a combination with a polyester patch (8)], autologous tissue [such as ribs, fascia, ilium, including vascularized iliac osteocutaneous flap (34)], or allografts [such as iliac bone allograft, cryopreserved allograft of cadaveric sternum (35)]. The most popular materials remain Marlex mesh with methyl methacrylate, which provide good incorporation into tissues and rigidity, or ePFTE patch with its malleability, inertness and resistance to infection. The main drawbacks of available prostheses are either insufficient support with a non-rigid prosthesis, or erosion of adjacent tissue with rigid ones (26).

Postsurgical mediastinitis following prosthesis contamination is a common and devastating complication reported in $8-20 \%$ for rigid and $5-25 \%$ for non-rigid materials that requires infected prosthesis removal (36).

Deschamps et al. (37) reported on 197 patients after chest wall resection and reconstruction at the Mayo Clinic. The authors have shown no significant difference in the postoperative outcome regardless of Prolene mesh or PTFE patch usage, and concluded that use of these materials is contraindicated in contaminated wounds.

Titanium plates are an excellent solution for skeletal reconstruction of large full-thickness defects with few reported complications such as plate fracture, dislocation and thoracic pain (32).

Chest wall defect coverage with soft tissue is an essential step of reconstruction and can be completed with a muscle flap (pectoralis major, latissimus dorsi, rectus abdominis muscles), myocutaneous flap, breast flap, or omentoplasty $(4,33)$. The greater omentum provides well vascularized tissue with a long pedicle, which allows the flexibility to design the flap with minimal donor defect. The advantages of a rich lymphatic network and ability to regenerate blood vessels make it an excellent tissue to use in areas of extensive radiation, recurrent infection, or when other local flaps have failed or are insufficient. In 1996, Arnold and Pairolero (38) summarized the experiences of 500 consecutive chest wall reconstructions at the Mayo Clinic, and omentum was used in $10 \%$ of patients. Rocco et al. (39) successfully used the omental flap interposition as a vascularized bed for a cryopreserved iliac crest homograft along with methylmethacrylate sandwiches, a myocutaneous flap and isolated skin graft in a complex chest wall reconstruction after recurrent chondrosarcoma resection. In another patient, the author wrapped an omental flap around titanium plates to prevent prosthesis contamination and to isolate it from mediastinal vessels and viscera, thereby preventing any friction from movement (40). Omentoplasty allows for coverage of large wounds too expansive for other 
tissue flaps, or in the case of high risk for prosthesis contamination, as we observed in our two cases. The most notable complication of the use of an omental flap is potential incisional hernia formation.

Free tissue transfer is used when regional flaps are insufficient, irradiated or previously failed. The internal mammary artery is an excellent inflow pedicle for the anterior chest wall (32).

Cryopreserved bone allograft with reduced immunogenicity, resistance to viral infection, osteoconductive and osteoinductive properties, and geometric configuration of the chest wall can serve as an alternative to autografts, allowing avoidance of complications at the donor site. Marulli et al. (35) demonstrated successful use of "rib-like" reconstruction with cryopreserved allograft of cadaveric sternum and attached costal cartilages fixed by titanium plates. In a subsequent series of 18 patients with allograft sternal transplantation, there were no reported complications related to the graft with a mean follow up of 36 months (41).

Complications after anterior chest wall reconstruction have been reported in $37-69 \%$ of patients with perioperative mortality up to $1 \%(37,42)$. Respiratory complications, with an incidence of $1.1-24.4 \%$, are the main source of morbidity after chest wall resections due to flail chest and paradoxical breathing with a $2-7 \%$ mortality rate $(26,42)$. Lardinois et al. (43) reported 26 cases of chest wall resection and reconstruction using the Marlex meshmethylmethacrylate "sandwich" technique. There was no mortality over 30 days. One prosthesis dislocation, one case of pneumonia, and two (8\%) prosthesis infections were observed. After removal of the prosthesis, pedicled omental and myocutaneous latissimus dorsi flaps were used for the reconstruction. No statistically significant difference between the preoperative and postoperative values of forced expiratory volume in 1 second was reported. Losken et al. (44) published a series of 200 patients undergoing chest wall resection. Chest wall reconstruction was done in $79 \%$ of cases with either synthetic mesh in 85 patients $(43 \%)$ and/or flap coverage (56\%). The most commonly reported complications were pneumonia (14\%), acute respiratory distress syndrome $(6 \%)$ and flap loss $(5 \%)$. Authors indicated mesh closure, delayed reconstruction, and radiation treatment were risk factors with an inpatient mortality rate of 7\%. Weyant et al. (26) reported a series of 262 chest wall resections followed by reconstruction. Prosthetic materials were used in $79.8 \%$ of patients, with a postoperative complications rate of $33.2 \%$. Respiratory complications were the most common and observed in
$11 \%$ of patients. Patient age (greater than 60 ), concomitant anatomical lung resection, and size of the chest wall defect were identified by multivariate analysis as significant predictive factors for postoperative morbidity. MMM reconstruction had no significant difference in respiratory complications compared with other types of reconstruction techniques, however, were associated with a greater number of wound infections. These findings corresponded to Kroll et al. (45), who showed a decrease in required duration of mechanical ventilation but a higher post-operative wound infection rate $(5 \%$ vs. $0 \%)$ with Marlex mesh stabilization. Lans et al. (25) published a retrospective study of 220 patients after chest wall resections. The independent predictive factors for post-operative complications, particularly wound healing problems, were ulceration of the tumor and omentoplasty. Gonfiotti et al. (5) retrospectively analyzed the experience of 41 chest wall reconstructions following primary chest wall resections. In the case of highgrade sarcomas, induction chemotherapy was performed in $12 \%$, adjuvant chemotherapy in $24 \%$, and radiation therapy in $12 \%$ of patients. Chest-wall reconstruction was carried out with prosthesis in $71 \%$ of cases: with nonrigid material (ePTFE or Marlex mesh) in $90 \%$, and rigid (MMM or STRATOS) in 10\%, with addition of muscular flap in $29 \%$. Paradoxical chest wall movements were observed in $11 \%$ of patients after non-rigid reconstruction without respiratory complications. Overall 5 -year survival rate in the chondrosarcoma group was $80 \%$. Bongiolatti et al. (13) reported 36 sternal resection and reconstruction, $50 \%$ of which for chondrosarcoma. Reconstruction was made using the STRATOS system combined with a muscle flap and/or PTFE (30.5\%), ePTFE patch (16.7\%), and bilateral pectoralis major myocutaneous advancement flaps (52.7\%). Delayed skin grafting was necessary in one case of total sternectomy for ulcerated tumor after a combined reconstruction with STRATOS and a pedicled left latissimus dorsi muscle flap. The overall complication rate was $19 \%$. Respiratory complications and wound infections occurred in $8 \%$ and $5.6 \%$ of patients respectively. Authors considered $3 \mathrm{~cm}$ as a safe margin away from the sarcomatous lesion with a better outcome $(\mathrm{P}<0.01)$. The independent predictor of survival was tumor grade: overall 5 -year survival rate was $100 \%, 83 \%$ and $0 \%$ for Grade I, II, and III, respectively.

\section{Conclusions}

This report serves to showcase two rare malignant neoplasms of the anterior chest wall that thoracic surgeons 
can encounter in their practice. Because of the rarity of these tumors, there are no clear guidelines in regards to treatment approaches. As a general rule, en bloc resection with wide margins is important to prevent local recurrence and improve 5-year survival in the case of malignancy. Resection of tumors involving the sternum is a challenging procedure and resulting full-thickness skeletal defects should be reconstructed to prevent paradoxical respiration. A small resected area after partial sternectomy could be reconstructed using an autologous bone graft, while larger defects require the use of artificial material. The preferred choice of prosthetic material and reconstructive technique is not settled. In the last few years, different techniques and materials have been described to reconstruct the anterior chest wall. However, this choice still remains the surgeon's preference and should be made by the combined efforts of both thoracic and plastic surgeons.

\section{Acknowledgments}

Funding: None.

\section{Footnote}

Reporting Checklist: The authors have completed the Narrative Review reporting checklist. Available at https:// dx.doi.org/10.21037/shc-21-8

Peer Review File: Available at https://dx.doi.org/10.21037/ shc-21-8

Conflicts of Interest: All authors have completed the ICMJE uniform disclosure form (available at https://dx.doi. org/10.21037/shc-21-8). The authors have no conflicts of interest to declare.

Ethical Statement: The authors are accountable for all aspects of the work in ensuring that questions related to the accuracy or integrity of any part of the work are appropriately investigated and resolved.

Open Access Statement: This is an Open Access article distributed in accordance with the Creative Commons Attribution-NonCommercial-NoDerivs 4.0 International License (CC BY-NC-ND 4.0), which permits the noncommercial replication and distribution of the article with the strict proviso that no changes or edits are made and the original work is properly cited (including links to both the formal publication through the relevant DOI and the license). See: https://creativecommons.org/licenses/by-nc-nd/4.0/.

\section{References}

1. Smith SE, Keshavjee S. Primary chest wall tumors. Thorac Surg Clin 2010;20:495-507.

2. Le Roux BT. Maintenance of Chest Wall Stability. Thorax 1964;19:397-405.

3. Burt M, Fulton $M$, Wessner-Dunlap S, et al. Primary bony and cartilaginous sarcomas of chest wall: results of therapy. Ann Thorac Surg 1992;54:226-32.

4. Marulli G, Duranti L, Cardillo G, et al. Primary chest wall chondrosarcomas: results of surgical resection and analysis of prognostic factors. Eur J Cardiothorac Surg 2014;45:e194-201.

5. Gonfiotti A, Santini PF, Campanacci D, et al. Malignant primary chest-wall tumours: techniques of reconstruction and survival. Eur J Cardiothorac Surg 2010;38:39-45.

6. Bawa HS, Moore DD, Pelayo JC, et al. Pediatric Chondrosarcoma of the Sternum Resected with Thorascopic Assistance. Open Orthop J 2017;11:479-85.

7. Fong YC, Pairolero PC, Sim FH, et al. Chondrosarcoma of the chest wall: a retrospective clinical analysis. Clin Orthop Relat Res 2004;(427):184-9.

8. Gao H, Zhou Y, Wang Z, et al. Clinical features and prognostic analysis of patients with chest wall chondrosarcoma. Medicine (Baltimore) 2019;98:e17025.

9. Widhe B, Bauer HC; Scandinavian Sarcoma Group. Surgical treatment is decisive for outcome in chondrosarcoma of the chest wall: a population-based Scandinavian Sarcoma Group study of 106 patients. J Thorac Cardiovasc Surg 2009;137:610-4.

10. Briccoli A, De Paolis M, Campanacci L, et al. Chondrosarcoma of the chest wall: a clinical analysis. Surg Today 2002;32:291-6.

11. McAfee MK, Pairolero PC, Bergstralh EJ, et al. Chondrosarcoma of the chest wall: factors affecting survival. Ann Thorac Surg 1985;40:535-41.

12. Gitelis S, Bertoni F, Picci P, et al. Chondrosarcoma of bone. The experience at the Istituto Ortopedico Rizzoli. J Bone Joint Surg Am 1981;63:1248-57.

13. Bongiolatti S, Voltolini L, Borgianni S, et al. Short and long-term results of sternectomy for sternal tumours. J Thorac Dis 2017;9:4336-46.

14. Ahmad U, Yang H, Sima C, et al. Resection of Primary and Secondary Tumors of the Sternum: An Analysis of Prognostic Variables. Ann Thorac Surg 2015;100:215-21; 
discussion 221-2.

15. Archontaki M, Stavrianos SD, Korkolis DP, et al. Giant Basal cell carcinoma: clinicopathological analysis of 51 cases and review of the literature. Anticancer Res 2009;29:2655-63.

16. Varga E, Korom I, Raskó Z, et al. Neglected Basal cell carcinomas in the 21st century. J Skin Cancer 2011;2011:392151.

17. Santos PJ, Prendergast C, Leis A. Giant Anterior Chest Wall Basal Cell Carcinoma: An Approach to Palliative Reconstruction. Case Rep Oncol Med 2016;2016:5067817.

18. Lorenzini M, Gatti S, Giannitrapani A. Giant basal cell carcinoma of the thoracic wall: a case report and review of the literature. Br J Plast Surg 2005;58:1007-10.

19. Lackey PL, Sargent LA, Wong L, et al. Giant basal cell carcinoma surgical management and reconstructive challenges. Ann Plast Surg 2007;58:250-4.

20. Cunnick GH, Sayer RE. Chest wall resection and reconstruction for metastatic basal cell carcinoma. Eur J Surg Oncol 1997;23:189-90.

21. Vallely MP, Stern HS. Giant anterior chest-wall basal-cell carcinoma. Eur J Cardiothorac Surg 2011;39:793.

22. Warbrick-Smith J, O'Neill JK, Wilson P. Giant anterior chest wall basal cell carcinoma: a reconstructive challenge and review of the literature. BMJ Case Rep 2013;2013:bcr2013008871.

23. Nystrom LM, Gibbs CP Jr, Singhal D, et al. Giant basal cell carcinoma of the anterior chest wall with bone invasion. Eur J Cardiothorac Surg 2014;45:945-6.

24. Unni KK. How to Diagnose Malignant Giant Cell Tumor. Pathology Case Reviews 2001;6:33-7.

25. Lans TE, van der Pol C, Wouters MW, et al. Complications in wound healing after chest wall resection in cancer patients; a multivariate analysis of 220 patients. J Thorac Oncol 2009;4:639-43.

26. Weyant MJ, Bains MS, Venkatraman E, et al. Results of chest wall resection and reconstruction with and without rigid prosthesis. Ann Thorac Surg 2006;81:279-85.

27. Astudillo R, Vaage J, Myhre U, et al. Fewer reoperations and shorter stay in the cardiac surgical ward when stabilising the sternum with the Ley prosthesis in post-operative mediastinitis. Eur J Cardiothorac Surg 2001;20:133-9.

28. Turna A, Kavakli K, Sapmaz E, et al. Reconstruction with a patient-specific titanium implant after a wide anterior chest wall resection. Interact Cardiovasc Thorac Surg 2014;18:234-6.

29. Watanabe A, Watanabe T, Obama T, et al. New material for reconstruction of the anterior chest wall, including the sternum. J Thorac Cardiovasc Surg 2003;126:1212-4.

30. Demetrian AD, Olteanu M, Mîndrilă I, et al. Long disease-free survival following total sternal resection and reconstruction of the sternum with acrylic cement for unique massive sternal metastasis after operated breast cancer. Rom J Morphol Embryol 2018;59:1225-32.

31. Zhang Y, Li JZ, Hao YJ, et al. Sternal tumor resection and reconstruction with titanium mesh: a preliminary study. Orthop Surg 2015;7:155-60.

32. Sanna S, Brandolini J, Pardolesi A, et al. Materials and techniques in chest wall reconstruction: a review. J Vis Surg 2017;3:95.

33. Chapelier A. Resection and reconstruction for primary sternal tumors. Thorac Surg Clin 2010;20:529-34.

34. Heller L, Huang WC, Chen HC, et al. Vascularized iliac bone flap used for sternum reconstruction after resection of chondrosarcoma. Plast Reconstr Surg 2002;110:1088-91.

35. Marulli G, Hamad AM, Cogliati E, et al. Allograft sternochondral replacement after resection of large sternal chondrosarcoma. J Thorac Cardiovasc Surg 2010;139:e69-70.

36. Thomas PA, Brouchet L. Prosthetic reconstruction of the chest wall. Thorac Surg Clin 2010;20:551-8.

37. Deschamps C, Tirnaksiz BM, Darbandi R, et al. Early and long-term results of prosthetic chest wall reconstruction. J Thorac Cardiovasc Surg 1999;117:58891; discussion 591-2.

38. Arnold PG, Pairolero PC. Chest-wall reconstruction: an account of 500 consecutive patients. Plast Reconstr Surg 1996;98:804-10.

39. Rocco G, Fazioli F, Scognamiglio F, et al. The combination of multiple materials in the creation of an artificial anterior chest cage after extensive demolition for recurrent chondrosarcoma. J Thorac Cardiovasc Surg 2007;133:1112-4.

40. Rocco G, Fazioli F, La Manna C, et al. Omental flap and titanium plates provide structural stability and protection of the mediastinum after extensive sternocostal resection. Ann Thorac Surg 2010;90:e14-6.

41. Marulli G, Dell'amore A, Calabrese F, et al. Safety and Effectiveness of Cadaveric Allograft Sternochondral Replacement After Sternectomy: A New Tool for the Reconstruction of Anterior Chest Wall. Ann Thorac Surg 2017;103:898-905.

42. Mansour KA, Thourani VH, Losken A, et al. Chest wall resections and reconstruction: a 25-year experience. Ann 
Thorac Surg 2002;73:1720-5; discussion 1725-6.

43. Lardinois D, Müller M, Furrer M, et al. Functional assessment of chest wall integrity after methylmethacrylate reconstruction. Ann Thorac Surg 2000;69:919-23.

44. Losken A, Thourani VH, Carlson GW, et al. A reconstructive algorithm for plastic surgery following

doi: $10.21037 /$ shc-21-8

Cite this article as: Gritsiuta AI, Bracken A, Abbas AE, Petrov RV. Complex anterior chest wall reconstruction after extensive oncologic resections: a narrative review. Shanghai Chest 2021;5:41. extensive chest wall resection. Br J Plast Surg 2004;57:295302.

45. Kroll SS, Walsh G, Ryan B, et al. Risks and benefits of using Marlex mesh in chest wall reconstruction. Ann Plast Surg 1993;31:303-6. 